\title{
Evaluating the demand side: New challenges for evaluation
}

Jakob Edler, Luke Georghiou, Knut Blind, Elvira Uyarra

Accepted for publication in Research Evaluation (2012)

Abstract

Evaluation of research and innovation policy faces radical challenges arising from a new policy emphasis upon demand-side measures and linked to this an understanding of innovation policy as a means to achieve societal goals. This paper considers the implications for the practice of evaluation at both micro and meso-levels. It uses the exemplar of an evaluation design for the European Union's Lead Market Initiative to expose the extent to which classical approaches to evaluation are valid and where new issues arise. Some problems highlighted include the difficulty of establishing a relevant baseline, the inability of public statistics constructed in supply-side mode to capture actions, the need to engage with actors who do not necessarily see themselves as part of the initiative being evaluated, long timescales and potential wide geographical scope, measures that span from micro to macro, and blurred boundaries between implementation and impact. It is concluded that there is a key role for evaluators to become involved in co-learning and coevolution of these policy instruments in a manner analogous to the relationship between evaluation and policy development that characterised the emergence of collaborative R\&D support programmes.

\section{Introduction}

The evaluation of research and innovation policy faces radical challenges within many OECD countries appears to be on the brink of two major, interrelated changes: (1) a turn towards more demand-oriented innovation policy and (2) an understanding of innovation policy as an instrument to achieve societal goals. For several decades, innovation policy across Europe, and beyond, has largely been defined and implemented as supply-oriented policy, supporting capacities to produce new knowledge and innovation. In recent years, however, a demand based approach to innovation policy has experienced a fresh start (Aho et al 2006, Georghiou 2007, Edler 2011, Lember et al 2007, OECD 2011, Myoken 2010) ${ }^{1}$. Those demand based approaches aim to identify, create and support demand for innovation. The instruments of demand based policies are broad and include public procurement of innovation, direct or indirect financial support for the purchase of innovations, various kinds of training and awareness mechanisms to build up and broaden absorptive capacity for innovation and the shaping of conducive regulatory framework conditions (Edler 2007, 2011, Rennings and Smidt, 2008). The basic idea is that demand can trigger and accelerate the production and diffusion of innovation and with it the production of scientific knowledge upstream and the creation of new, forward looking markets downstream.

1 The OECD Working Group on Science, Technology and Innovation Policy has started intensive activities to support demand based innovation policies; the discussions in this group have demonstrated that many countries have turned or plan to turn towards demand based policies (OECD 2011). 
A second major development is a stronger linkage of innovation policy with societal or economical goals. Triggered by the ERA Rationales report and related papers (Georghiou et al, 2008, Georghiou, 2008) a discussion in Europe has started that shifts the focus of innovation and research policy from being oriented in a broad but undefined way towards economic competitiveness in the first place to creating solutions for clearly defined "Grand Challenges". In this approach, the final purpose of the innovation is its contribution to societal or economical goals. Innovation policy thus turns much more explicitly into a means beyond economic policy, with innovation as an explicit means to societal ends. This requires a much more integrated policy approach, whereby traditional innovation and economic policy is integrated with other policy domains (Lengrand et al 2002). This concept now forms one of the key organising principles of the EU's central strategy for economic recovery, the Innovation Union Flagship within the EU 2020 initiative (EU COM 2010).

These rationales for demand based policies have diffused through the OECD world, and many countries are developing related innovation policy instruments and strategies (OECD 2011, Edler 2011, 2007). However, those policies are not based on or accompanied by policy evaluation. The evaluation of innovation policy has to date been founded and executed in the paradigm of supplyside innovation policies. These policies typically direct resources to innovation actors or seek to build their capabilities to innovate. (Metcalfe and Georghiou 1998, Edler and Georghiou 2007). Supply side policies are very diverse, ranging from support for investigator-driven research that feeds into innovation activity, grants for collaborative R\&D and fiscal incentives for R\&D more generally, support for the creation of start up companies, all sorts of networking and brokerage schemes and specific regulation to enable and foster innovation such as intellectual property rights. By contrast, the creation of incentives to innovate through the demand for innovation is largely passed by in evaluation frameworks. Reviews of evaluation of innovation policy have not revealed a body of practice (Papaconstantinou / Polt, 1997; Georghiou / Roessner, 2000, Edler et.al 2010). There is some evaluation tradition in the area of energy efficiency programmes, mainly in the US. However, those programmes are largely confined to diffusion of existing energy efficient products and thus the evaluations measure innovation only indirectly, and mostly are not geared towards measuring innovation capacity or performance. ${ }^{2}$ Thus, a recent OECD review of demand oriented innovation policies concludes that the "...lack of evaluation still makes evidence-based policy making in this area difficult. Therefore, better data and adequate evaluation metrics and methodologies are important to identify successful demand-side measures and to scale them up to larger scale initiatives." (OECD 2011, 12).

Further, recent examples in one of the central areas of demand policy, the use of public procurement to pull through goods and services that do not yet exist, have demonstrated this gap. For example, in Europe spending on innovation procurement appears as a recommended indicator in key advisory and policy documents (Barré et al. 2009, ERAB 2009) without any clear means to find reliable data. ${ }^{3}$ There are clear parallels to the emergence of collaborative R\&D programmes in the 1980s. These emerged more on the basis of beliefs held by policymakers than on clear evidence but a body of evaluation methods and results built up and co-evolved with the measures. The question is whether evaluation practitioners can similarly rise to the challenge today.

This paper seeks to address a severe evaluation gap. The shift of policy rationales and practice towards the demand side in recent years has turned the lack of evaluation concepts and methods for demand side innovation policies into an increasingly apparent shortcoming. With the possible

2 Evaluations of energy efficiency programmes employing demand side instruments can be found at http://iepec.org; or www1.eere.energy.gov/ba/pba/program_evaluation/evaluation_documents.html

3 In the US, examples of indicators and measurement exist, though, for example within the Federal Energy Management Program FEMP there is a requirement to refer to lists of energy efficient (and thus in principle products that are innovative or at least at an early stage of their life cycle) in tender processes and the compliance of procurers to that requirement can be monitored http://www.energystar.gov/index.cfm? c=fed_agencies.fed_ag_index. 
exception of the above mentioned, largely diffusion-oriented programmes in the energy sector, the demand for evaluation of those programmes clearly exceeds the capability of the evaluation community to supply what is desired. Without a better understanding of the potential impact of policies, on market and system failure they address and on the mechanisms by which policies can define and achieve goals, demand side policies remain an elusive concept where policy development follows intuition and is characterised by policy imitation rather than evidence, reasoning and informed learning.

The approach of this paper is to consider the implications of the broader rationales for demand-side innovation policies and then to explore the potential approaches to evaluation by considering an exemplar the European Lead Market Initiative, a policy instrument that exhibits several aspects of the demand-side approach. In so doing we track the four functions of strategic intelligence (see also Kuhlmann et al 1999): definition, conceptualisation, impact and formation as guiding principles of evaluation design.

\section{Demand Based Policies and Lead Market Stimulation}

In this paper, demand based innovation policies are defined as the set of public measures to articulate, increase demand for innovations and/or improve conditions for the uptake of innovations in order to spur innovation and their diffusion into the marketplace. Rather than substituting for them, demand-side policy measures operate alongside or in conjunction with supply-side measures. The basic rationale for demand-based policies rests on the following pillars:

- Creating incentives for innovators by overcoming system failures;

- Targeting innovations towards societal goals and policy needs (e.g. the Grand Challenges); and

- Promoting business development in a particular region/nation by exploiting lead market potential.

More traditional market failure arguments also hold here - those engaged in a purchasing decision for complex goods and services are unlikely to know the full range of what the market can offer in terms of innovation potential while those wishing to supply such goods and services may be unaware of unsatisfied needs in markets beyond their traditional customer base. Where network economies come into play the perceived risks of early purchase may deter the development of an innovation. The transaction costs involved in a switch to a new technology may be lowered by a public body making a commitment towards it by means of setting a standard or regulation or through its own acquisition of the technology. An evaluation of a demand-side policy needs to test both its underlying rationale and the way in which the implementation itself complies with this rationale.

There is a wide set of such demand based innovation policy instruments. One pillar with which the state influences innovation through demand is in its role as a purchaser. Hence public procurement is receiving increased attention (Edler / Georghiou, 2007, Uyarra/Flanagan 2010). The principal objective is to direct public purchasing towards innovations. We can distinguish between procurement that is responsive to existing innovation (as in diffusion oriented programmes such as the US FEMP programme), or procurement that is proactive, that triggers innovations as a new need is specified which requires a solution (Allmann et al. 2011). A variant of this, pre-commercial procurement, involves the purchase of R\&D rather than innovative goods and services. The best known example is the US Small Business Innovation Research initiative (SBIR). ${ }^{4}$

A second major pillar is support for private demand, most directly through demand subsidies in the form of direct payments, tax credits or exemptions, or some other financial advantage attached to the use of an innovation. Furthermore, state activity may systematically improve demand

4 Another early example has been the US Energy-Related Inventions Program (Brown et al 1994) 
competence of public and private costumers as one key enabler for the diffusion of innovation (Gatignon / Roberts, 1985) ${ }^{5}$. Following Porter (1990) and several other empirical studies (e.g. see von Hippel 1986), the more capable the users, the more likely it is that they will demand and adopt innovations. Policy may improve awareness (marketing support, state as lead user), skills (training, education, demonstration) and transparency (e.g. labelling, demonstration projects, etc.). Further, markets and innovations are shaped through all kinds of regulations (Blind 2010, 2012, Eto et al 1996) and support for defining and setting standards (see also Blind 2009). Even more fundamentally, the state can organize and support the articulation of demand, not only in reaction to existing innovations (risk discourse), but also in terms of trying better to understand societal preferences and their development and how they link to technological trajectories. Societal preferences are often not translated sufficiently well into signals to the market place - and needs are not heard, or technologies that do not reflect the risks they encapsulate might be pushed into the market. ${ }^{6}$ Both call for public action to support articulation of demand - in the public and the private sector (Smits, 2002).

Demand-side policies can be conceived at two levels - those which create the conditions in which demand engages with innovation (for example building capability, increasing incentives, reducing barriers, brokering to aggregate demand) and those which directly promote or subsidise the demand role in specific circumstances (for example through procurement of R\&D to demonstrator phases or direct subsidy for innovation procurement).

The actual policy measures in this domain range are quite varied. A categorisation would include:

- Policies to mitigate deficiencies in the flow of information between buyers and suppliers;

- Policies to improve the capabilities of those engaged in transactions to factor in innovation;

- Policies which subsidise procurement to offset additional risks taken on by purchasers of innovations(also in this category are guarantee or insurance-based schemes);

- Policies which seek to structure the market in favour of innovations (regulations and standards).

As we shall see, demand-based policies in this area do not easily lend themselves to "programmatisation" in the sense of having verifiable objectives, a schedule of deliverables and a budget. Still, we shall argue that some programme evaluation approaches, notably that of the logic chart, can be helpful in relating activity to objectives and effects at least where such a framework exists or can be constructed. Nonetheless, we have found that this is insufficient and that evaluation in this domain must cover the complete lifecycle from ex ante to ex post, and thus our notion of traditional evaluation in supply side policies needs to be broadened.

The demand based policy we explore in this paper as an exemplar is the support of the development of 'lead markets'. A lead market is one that exhibits a range of characteristics that make it suited for the introduction of certain innovations, which subsequently diffuse into other markets. For Bartlett and Ghoshal (1990), lead markets are 'the markets that provide the stimuli for most global products and process of a multinational company' (p.243, see also Beise 2004, Beise and Cleff, 2004). The cases of Japan, considered a lead market for the worldwide diffusion of the fax machine, and the Swedish and Finnish markets, key for the development of mobile cellular communication (Beise, 2004) are but some examples of lead markets.

In the current debate on lead market creation in Europe, such effects are often sought in areas in which the conditions are also favourable to the production of the innovation, thereby combining the diffusion effect with the primary economic effect. In Europe, the report of an EU expert group (Aho et al. 2006) triggered off a new debate around Lead Markets.

5 The energy efficiency programmes in the US, referred to in footnote 2, are prime examples of those competence and awareness enhancing programme (see http://iepec.org).

6 One means to overcome those asymmetries is constructive technology assessment, a process in which societal actors not directly involved in the production of a technology are included in the technology discourse at an early stage. 
The concept of lead markets is not new and it has been used to analyse the introduction and diffusion of products and technologies. However, the deliberate attempt to identify and support such markets through concerted policy action is new - and ambitious. It requires political will and high level consensus across different government departments on the aims, rationales and instruments to be used. Moreover, policy makers are faced with a set of challenges when they design, monitor evaluate and adjust Lead Market policies, which makes it necessary to employ a range of strategic intelligence tools in order to base the ambitious concept on the necessary evidence. We understand strategic policy intelligence (based on Kuhlmann et al. 1999) as all analytical and discourse tools that support the design, implementation and adjustment of policy by providing systematic evidence on underlying conditions and effects and by providing methods and tools that allow the stakeholders to reflect on goals, instruments and effects.

\section{Specific Considerations in the Evaluation of Demand-Side Policies}

The evaluation of demand-side policies needs to engage both at the micro and meso levels. At the micro level those designing an evaluation face a formidable challenge in establishing tests for additionality. At its most basic this approach involves establishing a counterfactual. A basic question concerns the extent to which demand was changed in scale, scope or quality by the intervention. It is difficult to deal with input additionality questions (whether an additional unit of input finance results in at least equivalent additional spend by the recipient) since specific financial expenditure on the policy may not be distinguishable either in the promoting agency or in the intended beneficiaries if it is embedded, for example, in wider procurement decisions. Even in the relatively straight forward case of subsidies provided for purchasers, these have to be balanced against the value of the reduction in risk.

For output additionality the comparison is between the cost of the measure and any benefits generated by the intervention. These could accrue to the purchaser of innovations resulting from or affected positively by the measure or to the suppliers in terms of increased capability and eventual greater sales.

It is likely that policymakers will not wish to be in a position of continual correction of the market and system failures and hence the issue of stimulating persistent changes in behaviour becomes an important policy objective. Such behavioural additionality may be achieved either by shifting the external incentive structure or by altering the internal routines of firms in favour of new behaviour. It is not difficult to map demand side policies into such a framework given that many, as we have discussed, are seeking either to alter the actual level of risk in innovation for a purchaser and their suppliers or their perceptions of that risk. Both of these may be achieved with the changes to resources, incentives and capabilities that were previously noted. From an evaluation perspective the interesting questions then become, how (and by how much) did the policy measures alter behaviour and have those new behaviours continued over time?

At the meso-level evaluation is more likely to be manifested as ex ante appraisal where rationales are established and realistic goals and targets articulated. Here the evaluation needs to engage with the context of the policy measure and be situated in a model or theory of systemic change, for example a realignment of research away from thematic approaches and towards societal challenges. From this rationale, in the simpler case of a demand side policy being conceived as a programme or initiative with bounded goals, timescale and budget, it is possible to follow the recommended evaluation approach of producing a logic model which sets out the goals in terms of their wider context and relates these to activities, outputs and outcomes. This is illustrated in the example given in this paper but it should be cautioned that a second category of demand side policies do not 
lend themselves so easily to this conceptualisation. ${ }^{7}$ Direct attempts to change behaviour through guidelines and training would come in the second group. This is not to say that these could not or should not be evaluated, only that cause and effect become harder to relate.

A macro level for evaluation could also be envisaged. This would seek to relate the broader economic and other framework conditions that structure demand for innovations to some measure of innovative performance. Increasingly indicators studies explore these characteristics but we shall not go further in this paper (Allman 2011, EU Com 2010).

\section{Early Experiences of Evaluation in this Domain}

As we only have limited experience of demand based innovation policy approaches, evaluation experience is scarce. A first evaluation of the Lead Market Initiative itself has been performed recently (SEES/Oxford Research 2011). This evaluation in fact, made use of major pillars of the concept we outline below, linking qualitative and quantitative methods (monitoring of market development indicators mainly). However, the approach was a classical ex post evaluation, and could not establish the entire cycle and breadth of methods and interactions as would ideally be expected in an evaluation of a complex demand side initiative.

Early attempts at evaluation on the demand-side had addressed diffusion policies, i.e. those policies that supported the buyer and adopter of new technologies (and services), largely firms. Many of those assessment approaches have been underdeveloped, mainly focussing on efficiency rather than outcome and impact in terms of influencing and strengthening demand (Stoneman/Diederen 1997 for the DTI studies), while others (Wengel et al. 1985) also looked at the induced changes in adopting firms and the overall diffusion effects, and more recently evaluation models for "deployment" programmes have been developed using systems and innovation diffusion theory (Reed/Jordan2007).

The most elaborated evaluation designs were applied to market transformation programmes, many of which done in the US (e.g. Gaffney, et al. 2011, Rubinstein et al. 2011, Russel, et. al. 2011), in Europe most prominently the Swedish Market Transformation Programmes (Neji 1998; Suvilehto/ Överholm 1998, Nutek 1994) and demand side management programmes organised via the International Energy Agency (Westling 1996). Those programmes tried to change the demand (and subsequently supply) in the markets for energy consuming products towards innovative, energy efficient products. The evaluations consisted of three pillars (Neji 1998,p. 2, Suvieltho / Överholm 1998): measuring change in purchaser behaviour (firms, retailers, consumers) through surveys and market analysis; development of the market (measured by market shares and prices, development of standards, changes in related infrastructure); and finally, impact on development of new technology as a consequence of more dynamic, innovation prone markets.

All of those evaluations used a combination of qualitative and quantitative measures and all applied time series analyses. The various evaluations overall claimed considerable success for the transformation programmes, at the same time highlighting the time lag between measures and effects, concluding that each evaluation of demand based measures faces time lag problems and thus runs the risk of under-estimating the overall effect of the measure.

As for public procurement, there are as yet no systematic evaluations done. The evidence we have builds on individual cases and the factors for their success (Edquist et al 2000, Edler et al 2006, Lember et al. 2007, EU COM 2009), but less with the actual effect of those procurement activities on markets and on public services. However, by analysing forensically the processes and impacts of concrete procurement cases, those studies point towards important dimensions to be considered by

7 Horowitz 2010 elaborates on logic models in the energy efficiency diffusion debate which focuses on the final impact of the policy, energy saving, rather than the innovation effect in terms of diffusion of energy efficient products. 
evaluations of demand based approaches that include public procurement: are procurers and other decision makers provided with the incentives and the legal pre-requisites to establish contacts with suppliers in order to learn about the technological possibilities? Do they develop the technological competencies needed to make innovation decisions well informed? Further, these analyses pointed towards the fact that innovation environments are very different between countries and highlighted the observation that public agencies and producers in 'immature environments' are much less able and likely to conduct innovation procurement.

Regarding the impact assessment of standards, as major elements of demand based policies - two separate traditions of impact assessment have to be considered. While we can observe a long tradition especially of ex post evaluation of R\&D programmes (Fahrenkrog et al. 2002; Ruegg, Feller 2003), the evaluation of standardisation processes or standards themselves is a rather rare and only recent phenomenon in the United States (Tassey 2003), where standard impact assessment is part of RTD evaluation, because of the assumption that standards are part of the technological infrastructure, which is provided by public institutions (e.g. the National Institute for Standards and Technology (NIST)). Meanwhile studies on the impacts of standards on growth (Blind and Jungmittag 2008 or trade performance (Swann et al. 1996 or Blind and Jungmittag 2005) of European countries have also been conducted using time series analysis as well survey-based impact assessment for specific standards, e. g. In the ICT field (Blind et al. 2010).

\section{A Conceptual Case Study: the European Lead Market Initiative}

As noted above, our exemplar is an evaluation concept for an early and prominent demand oriented policy in Europe, the European Lead Market Initiative. This concept was developed to support the European Commission in the implementation, assessment and fine-tuning of its initiative. While it highlights the major principles of a demand side evaluation, it describes mainly an approach for an interim and ex post evaluation. It was not meant to assist the design process of the initiative itself. Thus, the ideas on the first function, the market definition process, are kept short. The other three functions, conceptualisation, impact assessment and formation, are fully reflected in the concept. Before introducing the major steps and dimensions of the concept in section 5.2., section 5.1 first summarises the nature and scope of the Lead Market Initiative.

\subsection{The European Lead Market Initiative and demand on the evaluation}

The Lead Market Initiative (LMI) for Europe was adopted by the European Commission in December 2007 following the EU's 2006 broad based Innovation Strategy. The LMI is a combination of different policies, mainly public procurement, standards, other legislation and complementary actions. It was adopted on December 21st 2007 (EU COM 2007). The Commission identified six target markets: eHealth, recycling, renewable energy, sustainable construction, protective textiles and bio-based products. All of those six markets are defined around 'broad market segments' rather than a concrete range of products. The basic idea as stated by the Commission is not to pick winners, but to support broad areas in which different kinds of innovations can flourish. All areas are linked to wider societal needs (sustainability, efficient and effective health care etc.) and for all of them the Commission sees a strong economic potential within Europe that can be realised through concerted, coordinated and flexible action (ibid, p. 4).

For each of the six fields the Commission has defined concrete Action Plans with a timeline of 3-5 years. The action plans design a mix of demand-side policy measures:

- Legislation, i.e. to ensure that all regulation and legislation taken at European and ideally national level does not hamper innovation and is conducive to the needs of the specific potential Lead Market,

- Standardisation, certification and labelling, i.e. standard setting in Europe that is consistent with the demands of forefront technologies and demand in the selected areas, overcoming 
fragmentation and mobilising standardisation bodies to develop standards that set the direction also for global standardisation, improved European wide communication of standardisation needs and practices and mobilisation of standardisation platforms, support of self-certification and labelling in order to signal quality and leading edge innovation globally.

- Public procurement, i.e. to overcome fragmentation in public procurement markets across Europe, to help link procures across Europe through procurer networks, to support risk taking and market transparency through training and awareness measures and improved market discourse across Europe

- Flexible complementary activities, which range from improved information flows (eplatforms) to traditional innovation support measures (training, business management support) and finally financial support from various sources (Community Innovation Programme, the Framework Programme FP7, European Investment Bank etc.).

The latter, complementary activity, is seen as a way to insert flexibility into the concept and to allow for adjustments through mobilising additional instruments. Still, the overall mix of instruments is limited, there are, for example, no measures to link to public to private demand or measures to define the next generation of technologies in those markets through technology assessment and related research programmes - albeit that appropriate funds can in principle be mobilised within the European Framework Programme. The concept is ambitious and indeed new. There is no empirical predecessor for the deliberate creation of Lead Markets to draw from.

As the LMI is applied to six very different fields, an evaluation concept needs to be able to capture this heterogeneity to allow comparative analyses, but has to be flexible in order to take special characteristics of the specific markets into account. This also implies that the concept needs to get a sound understanding of the specific market situation, the technological trajectories and diffusion patterns, and the incentive structures of the key actor groups involved at the beginning of the initiatives, to best assess the difference the LMI makes.

In addition to being novel and heterogeneous, the LMI is complex. First, it applies a deliberate mixture of instruments. Therefore, an evaluation approach needs to be able to cover the interplay of measures as well as individual measures. Second, the LMI is a European instrument, whereby for all dimensions of the measures used, national and indeed regional administrations are the major players. Given this split responsibility at the various levels (and indeed across different units across the Commission) this European instrument needs a sound and effective coordination between the EU level and the national level and within these levels, both for the concept design and for its implementation - and any supporting strategic intelligence needs to foster this process. In doing so the concept can provide lessons for any multi-level context in which, for example, the setting of regulations and the public purchasing power may not be situated at the same policy level.

\subsection{The strategic intelligence concept for the LMI}

In the following section we present the evaluation concept for the LMI. As stated in the introduction, this does not serve to assess the LMI itself, but to illustrate the approaches and tools needed to assess it and in order to learn about how to evaluate those policies more generally.

\subsubsection{The overall evaluation logic}

Figure 1 depicts the overall evaluation logic comprised of four elements. The evaluation starts with (1) the definition of markets and societal challenges. This also includes the choice and delineation of the markets and the definition of appropriate indicators. It then covers the (2) conceptualisation, i.e. aspects of appropriateness (are the right things proposed? is the scale right?) and implementation (are the things done rightly). This is followed by an approach for assessing (3) effectiveness/impact on various levels, using both qualitative and quantitative indicators. The final step of the concept is to think of (4) how the evaluation can best accompany and support the design and implementation 
of the concept from the very beginning of the process (formation). The summary of this approach in the figure below also indicates the needs for indicators at the various stages.

\section{Figure 1: The Four Functions of Strategic Intelligence, the Evaluation Flow and Indicator Needs}

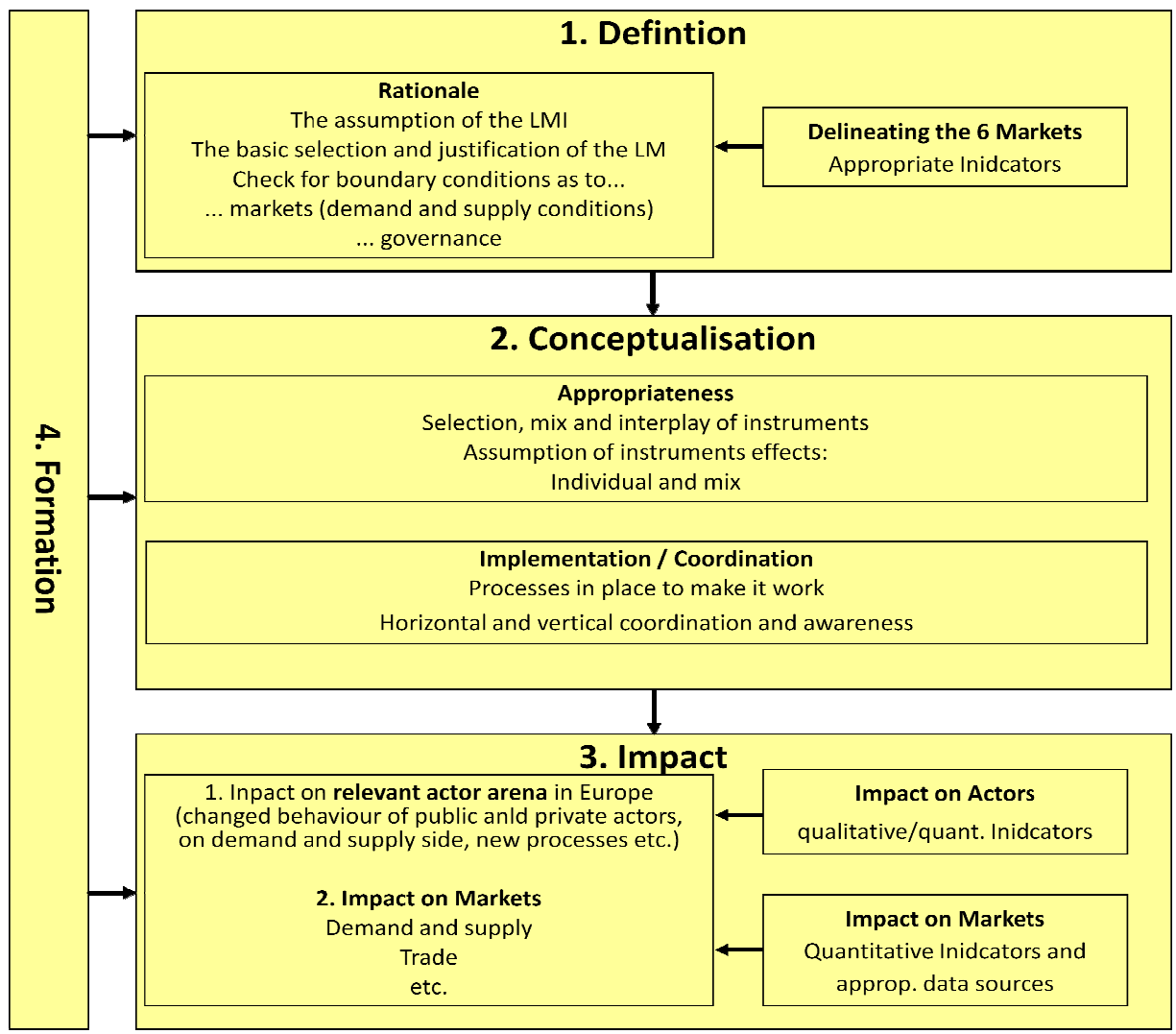

\subsubsection{Designing the basic policy model - and the basic for the evaluation}

As outlined in section 3, more than for other, less complex, policy measures, lead market policies need explicit and clearly communicated conceptualisation. First, there needs to be a clear understanding of the underlying rationale. The basic idea of pushing lead markets to make Europe more competitive and innovative and to tackle societal needs more effectively has been justified on the grounds of the Aho Group report as described above. For its application however, one has to check - for all six LM - if the conditions for lead markets as outlined above are realistically to be met, i.e. that the starting conditions are as such that LM policy is promising, This can be done with a check list for the various conditions that have been defined above.

Second, the overall coherence of the programme based on this rationale is to be made explicit and discussed with all major actors involved. Here, the instrument of a logic chart is a useful tool, ideally already used for the design of an initiative and then subsequently to be used as a guide for the evaluation and as a means of assessing the coherence of a programme over time. The logic charts has four roles:

- it sets out objectives, actions and impacts in a hierarchical structure as a guide to the effects that can reasonably be expected;

- it checks the logical consistency of an intervention - that is to say whether the actions can in any circumstances achieve the desired effects; and

- it forms an agreed basis for evaluation between evaluators on the one hand and those commissioning the evaluation or those being evaluated on the other.

- it demonstrates that effects are spread over time, immediate being those manifested while the programme/project is under way, intermediate those which are evident at the end of 
the programme/project and ultimate those which are manifested some time after completion.

Figure 2 below presents such a logic chart for the LMI. Although the LMI is not a traditional programme with clear identifiable and quantifiable goals and effects, and clear input - output relations, it still exerts a clearly identifiable cascade of effects and interplay of instruments. The logic chart illustrate this multi-step logic of the LMI in a very general sense, indicating which measures are designed to contribute to what intermediate effects and outcome across all six markets. It shows how the measures interact and how, in order to achieve final outcome, structures and behaviour need to change.

The model thus emphasises the need for a phased nature to the evaluation, whereby different phases follow the different stages of effects. Each stage is important in its own right, as the lack of effects at one level impedes effects down the line. The model signifies that during a first phase of implementation of the LMI it is likely that only immediate and some intermediate effects will be detectable. At the same time, this is the phase in which most formative support is needed, as actors need to understand why and how they need to change expectations and behaviours. For the evaluation of the LMI, a plan should be put in place for a more retrospective assessment of LMI, say 5 years after the start of the initiative. Before that time the evaluation can establish the baseline in the chosen markets, assess how well the activities are progressing and what effects they are having, and can produce informed projections about the likelihood of the outcomes being achieved. At the same time it can act as an instrument of learning, feeding back to the initiative and offering the possibility of mid-course corrections and a basis for the design of extensions or follow-ups. 
Figure 2: Logic Chart for LMI

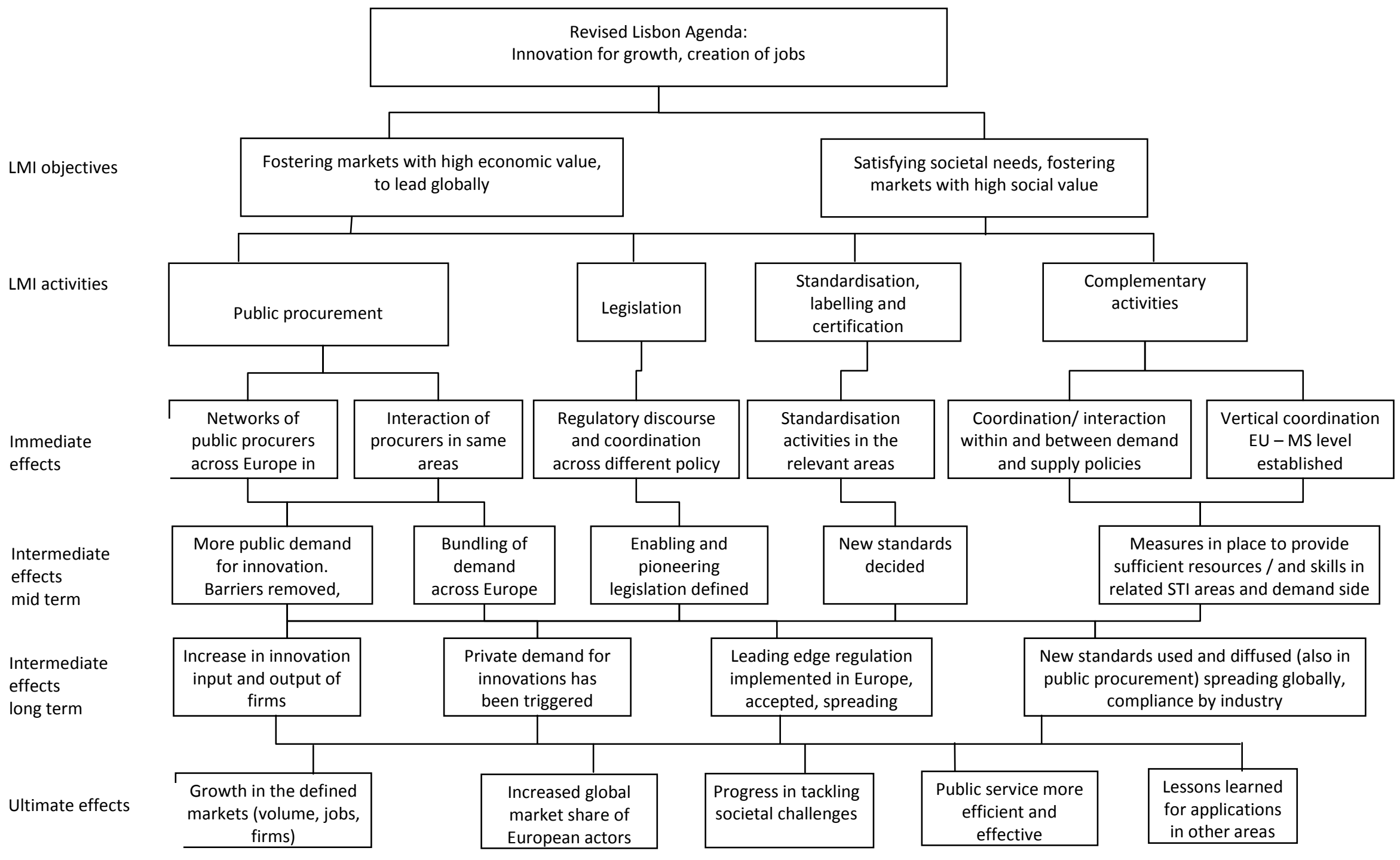




\subsubsection{Definition of societal needs and corresponding markets}

The second key challenge after defining a logical sequence of measures and effects is the definition of what exactly is to be supported, which need and which corresponding "market". In the case of the LMI, the Commission's justification for the selection of the chosen areas is that they are "highly innovative, respond to customers' needs, have a strong technological and industrial base in Europe and depend more than other markets on the creation of favourable framework conditions through public policy actions" (EU COM 2007: p.4). Thus, the assessment that the areas "respond to costumer's needs" has been defined as sufficient to trigger Lead Market development. While in all areas there is clearly a customer's or citizen's need, in a systematic process of strategic intelligence, this need would have to be defined more explicitly with more systematic consultation, extending to the scan of potential corresponding global needs that promise export potential.

For the implementation of the measure and its monitoring and evaluation, the needs and areas identified need to be matched with clearly defined markets so that market developments can be traced and target actors and institutional framework conditions can be identified. The delineation of those markets and the tracing of development in the markets can be approached in two ways. More traditionally, existing indicators and proxies for the definition of the six fields selected for the LMI can be derived according to the corresponding industrial sectors or product classifications. However, the six areas chosen do not easily fit to the given product classes or sector classifications. A second, often more suitable option for the definition of the area to target is through defining the demanders and other actors associated with the underlying societal need, as lead markets are about innovations to satisfy certain societal needs. In addition, the technological or procedural solutions may be developed by actors that are located in other market segments than those we would expect based on traditional, backward looking classifications. Therefore, the traditional approach needs to be open to dynamic changes. This means, as a principle, across all the six markets, an interview programme and a survey (adapted to the specific conditions in the lead market areas) of demanders (e.g. public procurers) would help to delineate markets and trace progress. To identify the buyers is rather straightforward, as they are directly linked to the (societal) need defined in the lead market. In addition, using key word searchers a procurement database, in this case the European database TED could be scanned in order to identify public procurers and if feasible, the winning companies in related bids (TED contains for some tenders the name of the successful firm only). ${ }^{8}$ Again, this interaction with the target group and the discussion about the target group with those administrators responsible for the LMI would be a part of the formative evaluation, it would establish the basis for a monitoring and a reflective discourse throughout the implementation.

\subsubsection{Appropriateness (are the right things done) and implementation at market level}

For the assessment of appropriateness and the implementation of the LMI for each individual market we have to distinguish between two levels: individual measures (e.g. public procurement networks) and the overall orchestration of the instrument mix. To start with the latter, in a variety of areas the concept of "policy mix" has been gaining ground (Flanagan et al, 2011), based upon the observation that policies and their instruments interact with each other, creating on the one hand the potential for synergies and on the other the need to avoid where possible policies which offset the benefit of each other (for example a fiscal incentive has less impact if the overall level of taxation is reduced).

There are also consequences for evaluation. For the LMI the main challenge is that the individual initiatives may be the responsibility of different actors, responding to different governance structures. Evaluating them independently may neglect the potential for detecting the interactive effects described above, and may blur the actual attribution of effects to instruments. In the realm

8 For the analysis of impact, such a procurement analysis would be desirable on a global scale as well, however, we lack a database beyond Europe comparable to TED 
of innovation policy the normal way in which this issue is addressed is to carry out system level evaluations which look at the effectiveness of the instruments synchronously and with a view to detecting systemic failures, for example of linkage (Arnold 2004, Edler et al 2008). Thus, we would look at the overall policy mix just as well as the (necessary) changes of governance structures themselves.

As for the appropriateness of the mix, the evaluation concept therefore needs to ask for each market: Are demand measures enough to trigger development and production of innovations, are the bottlenecks for a certain technology also of a technological nature? If so, what is done to overcome them? Equally, are there any second generation issues that need to be engaged to be at the forefront of the transition of the future market?

At the level of individual instruments the major purpose for the evaluation of appropriateness is to ask if the various measures are linked to the underlying need, if there is leverage for policy intervention to make a difference and if the assumptions for the various instruments in terms of demand bottlenecks that are targeted with the measures are right? Means to gather the data and find answers to these instrument specific and cross instrument questions can include a survey of and interviews with buyers (or potential buyers) and participants in standardisation processes, supplier surveys (to understand the nature of market and system failure from a supplier perspective) and analysis of legal texts and tender documents.

The evaluation procedure for the question around implementation is similar in terms of getting data, as with appropriateness this analysis is largely based on qualitative data (document analysis, interviews and various surveys would have to be conducted). The evaluation needs to examine the process of implementing the chosen instruments and coordinating this implementation, horizontally (across different DGs), vertically (between policy levels) and finally between all stakeholder groups at those levels. In other words, this step needs to analyse the management of transition towards action that is conducive to develop the Lead Market. For the overall orchestration of the instruments this covers issues such as general awareness in policy, administration and related businesses, transparency, time consistency (right order of measures), cross-referencing of measures, including supply side measures if and as needed. Again, for the individual measures the questions to explore are about participation, about actual activities around procurement (e.g. best practice groups, training, new ways of tendering etc.) and standardisation and legislation (e.g. innovation conducive nature of standards and regulation, coordination of standards with other legislation, lead function of European standards and legislation for other parts of the world and so on).

\subsubsection{Impact}

Impact assessment of the LMI needs to capture three levels of impact:

- the actor arena shaping the market conditions (intermediary actors), i.e. procurers, standard setting bodies and norm setting actors and other regulative bodies in the multi-level setting

- the reactions of market actors to improved market conditions and demand signals

- the market development itself.

In assessing impact on those three levels, a mix of methods and data sources is needed, to capture change in behaviour and attitudes of actors as well as diffusion of innovations and their impact on social well-being. Further, the time scale and the attribution challenge need to be kept in mind. Following the logic chart model, some of the impacts are more immediate, while others will take a series of years to unfold.

For the assessment of impact in terms of changes in actor behaviour and attitudes and implementing structures the same data sources and tools can be applied as outlined above for implementation. The key analytical dimensions to cover document analysis, surveys, interviews and case studies are the actual actions and intentions of actors, and to identify changes in those 
behaviours and actions that are attributable to the policy intervention. Table 1 gives one example for all four instrument dimensions, again for one specific Lead Market, protective textiles.

\section{Table 1: Impact questions for the LMI - example of personal protective equipment (PPE)}

\begin{tabular}{|l|l|}
\hline $\begin{array}{l}\text { Overall approach, } \\
\text { mix }\end{array}$ & $\begin{array}{l}\text { In addition to the market development impact based on the indicator and survey proposed: } \\
\text { Has the market become more innovation and competition driven, e.g. do we see more firm entries, } \\
\text { more variety of products, greater product differentiation etc. ? } \\
\text { Have the actions taken influenced specific context conditions of the defence area (defence } \\
\text { procurement, established networks, traditionally more nationally closed markets). }\end{array}$ \\
\hline Procurement & $\begin{array}{l}\text { Are procurers across Europe more aware of benefit in process innovation? } \\
\text { Are procurers more aware of the functionalities of innovative PPE } \\
\text { Have tender texts changed significantly (functional specification, value for money, variants, link to } \\
\text { leading edge standards as minimum requirements etc.) } \\
\text { Is there increased and upgraded procurement activity also in services related to PPE? } \\
\text { Have similar public services across countries coordinated and bundled their demand } \\
\text { Are SMEs among the winners, any increase in their share? Do we see changes in SME involvement } \\
\text { in supply chains? } \\
\text { Has the share of leading edge protective textile products in public procurement increased } \\
\text { significantly? Are the products purchased increasingly leading edge? }\end{array}$ \\
\hline Standards & $\begin{array}{l}\text { Are EU standards becoming international standards? } \\
\text { Have voluntary certifications become more common, and are users better aware? }\end{array}$ \\
\hline Legislation & $\begin{array}{l}\text { Are the European regulations being accepted outside the EU? Have producers in Europe made use } \\
\text { of improved design registration (link to WIPO)? }\end{array}$ \\
\hline $\begin{array}{l}\text { Complementary } \\
\text { Actions }\end{array}$ & $\begin{array}{l}\text { Is there greater awareness as for need for PPE, greater willingness to pay leading edge premium } \\
\text { across Europe? } \\
\text { What share of stakeholders is better informed about opportunities, both supply and demand side? } \\
\text { Through what channels? } \\
\text { Does RTD funding system provide enough support for next generation? } \\
\text { Have financing opportunities been improved, has there been a piloting of innovation platforms? }\end{array}$ \\
\hline
\end{tabular}

As regards market development, the indicators are needed for the various dimensions of the market development (absolute numbers of sales, shares, international trade, patents, number or producers etc.) and to define the appropriate data sources to collect the data in line with the market delineation as outlined above. As the concept covers Lead Markets, indicators will - in principle have to capture weak signals early, thus this may go beyond turnover and export statistics, and include investment data, patent data, trademark data, company foundation data and data related to the implementation of the policy instruments, like public procurement data (CVP data), regulation data taken from the TRIPS database, and data from standards data bases.

\subsubsection{Basic Evaluation Implementation Design}

After having outlined the major conceptual steps of the LMI evaluation, a basic implementation design can be formulated, giving an overview about division of labour and methods used. Figure 3 summarises this design. It shows that three evaluation steps have to be performed in order to be able to evaluate the LMI along the logic chart presented above: (1) market delineation, (2) formation of and impact on actors and (3) impact on markets. It is a specific feature of demand based policies that they need to combine in-depth knowledge and expertise on the demand side, on markets, their delineation and monitoring (indicators) and on the various kinds of market and system failures on the one hand and in-depth methodological knowledge on evaluation processes and techniques on the other hand. 


\section{Figure 3: The evaluation design for the LMI}

\section{Central Evaluation Team responsible for}

policies, methods, coordination, cross-market learning and synthesis

\section{Market specific teams (Task Force and external consultants):} specific markets (actor and specific indicator knowledge)

\begin{tabular}{|l|l|l|l|l|l|}
\hline $\begin{array}{l}\text { Team A } \\
\text { Construction }\end{array}$ & $\begin{array}{l}\text { Team B } \\
\text { Textiles }\end{array}$ & $\begin{array}{l}\text { Team C } \\
\text { Bio-based }\end{array}$ & $\begin{array}{l}\text { Team D } \\
\text { Recycling }\end{array}$ & $\begin{array}{l}\text { Team E } \\
\text { Renewables }\end{array}$ & $\begin{array}{l}\text { Team F } \\
\text { eHealth }\end{array}$ \\
\hline
\end{tabular}
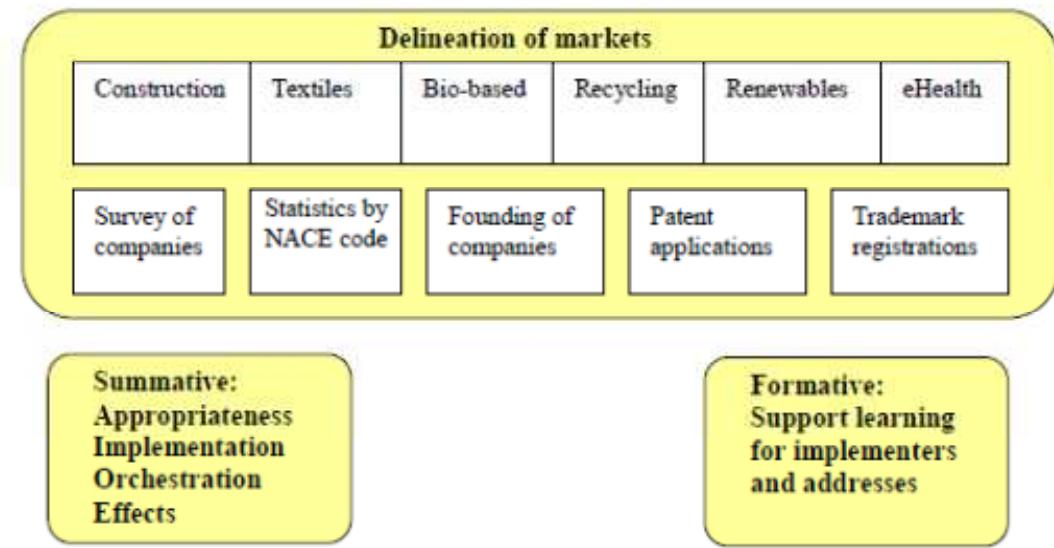

Formative:

Support learning

for implementers

and addresses
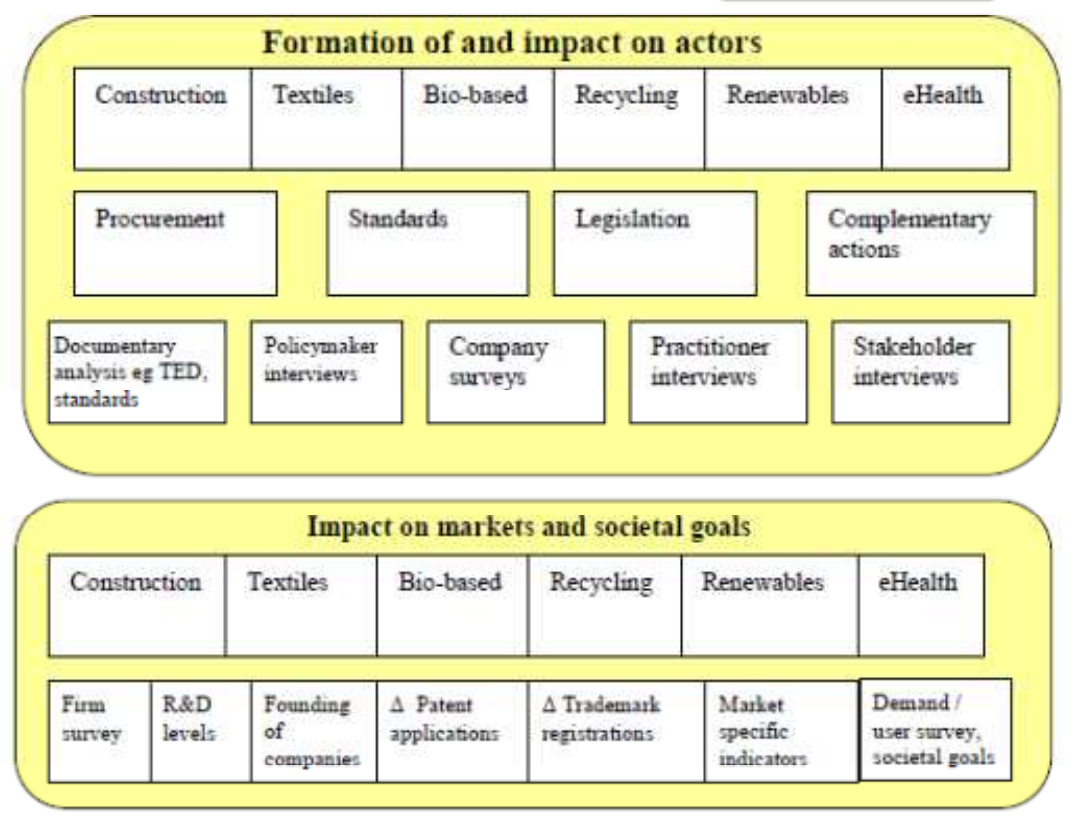

When coping with these challenges and to conduct evaluation of a novel instrument in six diverse markets, in our example of the LMI we developed a matrix structure for the implementation of the evaluation. As the six markets are so complex and indeed very different in the actor representation and in the ways they can be delineated and economic developments can be measured, a pragmatic suggestion in this specific case it to have six specialised market teams (MT) with a sound background in those markets and related technologies. The six market teams would in principle be responsible for a delineation of the markets, of identifying the actors, and of defining the indicator with which market developments can be traced. Ideally, external consultants would be linked with the EU 
Market Task Forces who would deliver regular monitoring data. The MTs would not necessarily have to neither be familiar with specialised evaluation methodologies nor have initial in-depth knowledge of all the relevant policy measures, key is their market expertise. The overall evaluation could be led by a horizontal evaluation team (HET) which would be responsible for guiding the analysis of the individual policies, the governance and contextual issues and provide the methodological toolbox for the evaluation. The latter includes knowledge on formative practices (workshops, interviews, etc.) as well as specialised methods such as tailored evaluation surveys and patent analysis. The HET would work closely with the MT to bring the methodological knowledge and the actor/technology/market knowledge together.

\section{Lessons and challenges remaining}

For a variety of reasons, among them costs and a lack of initial involvement in the design and implementation phase, the actual evaluation of the LMI conducted in 2011 (2011 SEES/Oxford Research 2011) was influenced by but did not follow all elements of the schedule set out here.

We selected the LMI evaluation concept because it contained and combined elements of several major strands of demand-side innovation policy. Hence by exploring this exemplar we may cast some light upon the emergent practice of evaluating demand-side policies. The principles and components of the design here could be reassembled to engage with other demand-side interventions, either those using individual policy instruments or, as in this case, a combination. At the level of rationale and ex ante evaluation we have seen that market and system failure rationales are both evident and hence should be tested. This implies that an evaluation should connect at least the micro and the meso if not the macro levels. Ex ante evaluation is essential to create a baseline and to delineate the meso environment but there are major challenges here. The pre-existing market is some kind of baseline but the very act of innovating means that the market is redefined and hence the most obvious measures such as the market shares of innovators or their export behaviour are less likely to be valid. The greater the degree of transformation the more significant this effect becomes.

Data issues are also challenging. Unlike R\&D, few public statistics measure the activities we are interested in. Public actors are normally aware of the level of their procurement budgets but only a small minority have sought to classify it in terms of the proportion of activity which is directed towards innovative activities - this is equally true for procurement and for regulation. Indeed this could be an important benefit of evaluation - without such measurement the level of awareness of a policy and its effects is bound to remain low. On the positive side there is increased pressure for such measurement to enter the toolbox of innovation surveys; once it has the task of the evaluator will be eased. ${ }^{9}$

Measurement difficulties are not confined to the market. The actors being coordinated do not necessarily see themselves as part of the initiative even where such an initiative exists and the likely spillovers will involve further actors with little or no connection or awareness of the activity but who have responded to the incentives, capabilities or resources put in place by the policymaker. Without the link of a contract, access can be a problem. The issue of ownership also extends to the setting for

9 The actual evaluation of the LMI as conducted illustrates this challenge: It applied - with some changes the quantitative indicators suggested and followed the major dimensions of the interview programme. In correspondence with what this article argued, the evaluation report illustrates a set of methodological challenges Most importantly, it tries to measure all sorts of innovation and market effects quantitatively that one would expect to take much more time to realise as a consequence of the complex LMI. This is exacerbated by the fact that a clear baseline for markets and actor behaviour was not established sufficiently, as existing databases do not match what is defined as a lead market and - more generally - fail to monitor change in market delineation as a consequence of innovations and new suppliers entering the market (2011 SEES/Oxford Research 2011, p.28). 
the evaluation. Innovation policymakers tend to be specialists in issues such as technology transfer and are not always equipped or even senior enough to carry out the cross-government brokerage that demand-side approaches entail.

Furthermore, if we recall the four functions of strategic intelligence, (1) definition, (2) conceptualisation, (3) impact and (4) formation as guiding principles of evaluation design, our concept has demonstrated that it is important to give equal weight to all four functions. We must stress, however, that due to the novelty and complexity of demand based measures as explicit innovation policies definition, conceptualisation and formation appear to be of utmost importance. If, for example, the initial definition of the rationale is not thought through and conceptually - and explicitly - linked to the various measures and expected causal links (conceptualisation), not all of the effects of a measure will be captured. Thus, the reason for success or failure will not be traceable and learning of all stakeholders will be limited. The report of the limited implementation of the LMI concept illustrates this nicely, noticing the challenges arising out of the fact that the initiative failed to define goals for all the elements of the entire logic of the initiative (as outlined above) at the outset, which then led to follow up problems of finding evidence in a transparent way (SEES/Oxford Research 2011, executive summary).

Finally, as with most issues in the domain of innovation, there are often long timescales and in this case there is also potential wide geographical scope. The timing and positioning of an evaluation will be forced into a compromise between delivery in time to support the design of the next generation of policy and the likelihood that too early an attempt to evaluate will most likely only find the weakest of effects even if activity can be identified. This is likely to involve evaluations hovering on a blurred boundary between implementation and impact - not unfamiliar territory but not desirable.

How then to move forward? It should be recalled that much of the current standard practice of evaluation of innovation policy was formed in the crucible of grappling with an earlier generation of policy innovation - that of collaborative R\&D. Founded in the 1980 s by the year 2000 it was possible to observe (Georghiou and Roessner, 2000) a co-evolution between the development of the instrument and the development of evaluation practice. Both had faced vocal criticism in their early period and both came to be regarded as standard practice as they moved up the learning curve. Demand side innovation policy stands to benefit in the same way if the evaluation community can rise to the challenge.

\section{References}

Aho, E., Cornu, J., Georghiou, L., Subira, A. 2006. Creating an Innovative Europe. Report of the Independent Expert Group on R\&D and Innovation appointed following the Hampton Court Summit. Luke Georghiou, Rapporteur

Allman, K.; Edler, J.; Georghiou, L.; Jones, B., Miles, I.; Omidvar,O.; Ramlogan, R. Rigby, F. (2011): Measuring wider framework conditions for successful innovation, NESTA report, January 2011

Arnold, E. 2004. Evaluation Research and Innovation Policy: A Systems World Needs Systems Evaluations. Research Evaluation, 13(1), 3-17.

Barré, R., Regibeau, P., Lepori, B., Siedschlag, J, Soboll, H., Tubbs, M, Veugelers, R., Ziarko, W. 2009. ERA indicators and monitoring. Expert Group Report, Brussels $\mathrm{ftp}: / / \mathrm{ftp}$.cordis.europa.eu/pub/era/docs/era_indicators\&monitoring.pdf

Bartlett, C. A., Ghoshal, S. 1990. Managing innovation in the transnational corporation. In: C.A. Bartlett, Y.L. Doz and G. Hedlund (eds.) Managing the Global Firm, pp. 215-255. London (UK) New York (US and Canada): Routledge.

Beise, M. 2004. Lead markets: country-specific drivers of the global diffusion of innovations. Research Policy, 33 (6-7): 997-1018. 
Beise, M., Cleff. T. 2004. Assessing the lead market potential of countries for innovation projects'. Journal of International Management, 10(4): 453-477.

Blind, K. 2009. Standardisation: a catalyst for innovation. Inaugural Address delivered at the occasion of accepting the appointment as extraordinary Professor of Standardisation on behalf of NEN, the Netherlands Standardisation Institute, RSM, Rotterdam.

Blind, K. 2010. The Use of the Regulatory Framework to Innovation Policy. In: R. Smits, P. Shapira and S. Kuhlmann (eds.) The Theory and Practice of Innovation Policy - An International Research Handbook, pp. 217-246, Cheltenham: Edward Elgar.

Blind, K. 2012. The Influence of Regulations on Innovation: A Quantitative Assessment for OECD Countries. Forthcomimg in Research Policy 2012.

Blind, K., Gauch S., Hawkins, R. 2010 How stakeholders assess the impacts of ICT standards. Telecommunications Policy, 34 (3): 162-174.

Blind, K., Jungmittag, A. 2005. Trade and the Impact of Innovations and Standards: The Case of Germany and the UK. Applied Economics 37, pp.1385-1398.

Blind, K., Jungmittag, A. 2008. The Impact of Standards and Patents on Macroeconomic Growth: A Panel Approach Covering Four Countries and Twelve Sectors. Journal of Productivity Analysis, pp. 51-60.

Brown, M., A.; Wilson, C.R.; Franchuk, C.A. 1994. The economic, energy and environmental impact of the energy-related inventions program. Prepared for the Office of Energy Efficiency and Renewable Energy U.S. Department of Energy, Washington http://www.osti.gov/accomplishments/documents/fullText/ACC0016.pdf

DTI 1987. An evaluation of the Manufacturing Advisory Service, Assessment Paper 1, London.

Edler, J. 2007. Bedürfnisse als Innovationsmotor. Berlin/Karlsruhe: Sigma.

Edler, J. 2010 Demand Oriented Innovation Policy. In: R. Smits, S. Kuhlmann and P. Shapira (eds.), The Theory and Practice of Innovation Policy An International Research Handbook, pp. 275 - 302 Cheltenham: Edward Elgar.

Edler, J. 2011. Innovation in EU CEE: the role of demand-based policy. In: S. Radosevic and A. Kaderabkova (eds.), Challenges for European Innovation Policy. Cohesion and Excellence from a Schumpeterian Perspective, pp. 177-208, Cheltenham (UK) Northhampton (US): Edward Elgar.

Edler, J., Ebersberger, B, and Lo, V. 2008 Improving policy understanding by means of secondary analyses of policy evaluation. Research Evaluation 17, 175-186.

Edler, J., Edquist, C., Georghiou, L., Hommen, L. Hafner, S., Papadakou, M., Rigby, J., Rolfstam, M., Ruhland, S., Tsipouri, L. 2006. Innovation and Public Procurement. Review of Issues at Stake, final report, Brussels [ftp://ftp.cordis.lu/pub/innovation-policy/studies/full_study.pdf)].

Edler, J., Georghiou, L. 2007. Public procurement and innovation - Resurrecting the demand side. Research Policy 36(7): 949-963.

Edler.J., Amanatidou, E., Berger. M., Bührer., S:, Daimer, S:, Dinges, M., Garefi., I.,. Gök., A., Schmidmyer., J. 2010. INNO-Appraisal. Understanding Evaluation of Innovation Policy in Europe. Brussels / Manchester.

Edquist, C., Hommen, L., Tsipouri, L. 2000. Public technology procurement and innovation, Boston: Kluwer Academic.

ERAB 2009. Preparing Europe for a New Renaissance: A Strategic View of the European Research Area. First annual report.. Brussels.

Eto, J.; Prahl, R.; Schlegel, J. 1994. A Scoping Study on Energy-Efficiency Market Transformation by California Utility DSM Programs. Berkeley.

EU COM 2007. A Lead Market Initiative for Europe, COM (2007) 860 final (Brussels). 
EU COM 2009. Exploring Public procurement as a Strategic Innovation Policy Mix Instrument. Final report of the EU funded OMC - PTP project; http://www.innovation.lv/ino2/publications/Publicprocur.pdf

EU COM 2010. Innovation Union. Brussels, SEC(2010) 1161.

Fahrenkrog, G., Polt, W., Rojo, J., Tubke, A., Zinöcker, K., et al. 2002. RTD evaluation toolbox assessing the socio-economic impact of RTD policies (EUR $20382 \mathrm{EN}$ ) Seville (Download: www.jrc.es/home/publications/publication.cfm?pub=1045 (2002)

Flanagan, K., Uyarra, E., Laranja, M. 2011. Reconceptualising the 'policy mix' for innovation. Research Policy, 40(5): 702-713.

Gaffney, K., et al. 2011. Residential Lighting: Shedding Light on the Remaining Savings Potential in California. Proceedings of the IEPEC. Boston: August 2011.

Gatignon, H., Robertson, T.S. 1985. A Propositional Inventory for New Diffusion Research. Journal of Consumer Research, 11 (March), 849-867.

Georghiou L. 2008. Europe's Research System Must Change. Nature, 452(24): 935-936.

Georghiou, L. 2007. Demanding Innovation: lead markets, public procurement and innovation, NESTA Provocation 02: February 2007, London NESTA

Georghiou, L., Cassingena Harper, J., Cooke, P., Cozzens, S., Dearing, A., Henriques, L., Langer, J., Laredo, P., Sanz Menendez, L., Weber, M. 2008. Challenging Europe's Research-Rationales for the European Research Area, European Commission EUR 23326 EN

Georghiou, L., Roessner, D. 2000. Evaluating Technology Programs: Tools and Methods. Research Policy, 29(4-5): 6.

Horowitz, M., J. 2010. Measuring the savings from energy efficiency policies: a step beyond program evaluation; in Energy Efficiency 4(1), 43-56, March 2010. DOI 10.1007/s12053-010-9082-6

Kuhlmann, S. et al. 1999. Improving distributed intelligence in Complex Innovation Systems. Final Report of the Advanced Science \& Technology Policy Planning Network (ASTTP). KarlsruheKuhlmann et al. 1999

Lember, V., Kalvet, T., Kattel, R., Penna, C., Suurna, M. 2007. Public Procurement for Innovation in Baltic Metropolises- Case Studies, Talinn; http://www.tallinn.ee/est/g2420s33519

Lengrand, L. et al. 2002. Innovation tomorrow, innovation policy and the regulatory framework: making innovation an integral part of the broader structural agenda. Luxemburg: EUR 17052, Directorate-General for Enterprise, European Commission.

Metcalfe, J., Georghiou, L. 1998. Equilibrium and Evolutionary Foundations of Technology Policy. STI Review, No. 22. Special Issue on "New Rationale and Approaches in Technology and Innovation Policy". Paris: OECD.

Myoken, Y. 2010. Demand-orientated policy on leading-edge industry and technology: public procurement for innovation. International Journal of Technology Management, 49 (1/2/3): 196219.

Neji, L. 1998. Evaluation of Swedish Market Transformation Programmes. Lecture at the ACEE Summer Study on Energy Efficiency in Buildings, Panel II.

NUTEK 1994. Effective Market Influence - an effect chain analysis of NUTEK's high frequency lightning campaign. Report R 1994:70, Stockholm

OECD 2011. Demand side innovation policy. Paris http://www.oecd-ilibrary.org/science-andtechnology/demand-side-innovation-policies_9789264098886-en

Papaconstantinou, G., Polt, W. 1997. Policy evaluation in innovation and technology: An overview. Introductory chapter to the Proceedings from OECD Conference on Policy evaluation in innovation and Technology, Paris June 26-27th 1997, http://www1.oecd.org/dsti/sti/statana/prod/evaluation.htm.

Porter, M. E. 1990. The competitive advantage of nations, Free Press: New York. 
Reed, J. H.; Jordan, G, 2007. Using systems theory and logic models to define integrated outcomes and performance measures in multi-program setting, Research Evaluation 16 (3), 169-181(13)

Rennings, K., Smidt, W. 2008. A Lead Market Approach Towards the Emergence and Diffusion of Coal-fired Power Plant Technology. ZEW Discussion Paper No. 08-058

Rubinstein E. et al. 2011. Can Market Effects from CFL Programs be Measured? Let Us Count the Ways. Proceedings of the IEPEC, Boston: August 2011.

Ruegg, R., Feller, I. 2003. A Toolkit for Evaluating Public R\&D Investment, Models, Methods, and Findings, from ATP's First Decade. Prepared for Economic Assessment Office, Advanced Technology Program, National Institute of Standards and Technology. Gaithersburg, Md.: National Institute of Standards and Technology, Technology Administration, U.S. Department of Commerce, July 2003.

Russel, C. et. al. 2011. Net Impacts from Upstream Lighting Programs: A Multi-State Model. Proceedings of the IEPEC, Boston: August 2011

SEES / Oxford Research 2011. Final Evaluation of the Lead Market Initiative. Final Report July 2011 http://ec.europa.eu/enterprise/policies/innovation/policy/lead-market-initiative/files/finaleval-Imi_en.pdf

Smits, R. 2002. Innovation Studies in the 21st Century. Questions from a User's Perspective. Technological Forecasting and Social Change, 69, 861-883.

Stoneman, P, Diederen, P. 1997 Technology Diffusion and Public Policy. The Economic Journal 104 (425), pp. 918-930.

Suvilehto, H.-M., Överholm, E. 1998. Swedish Procurment and Marcet Activities - Different Design Solutions on Different Markets. Presentation at the 1998 ACEEE Summer Study on energy efficiency in buildings.

Swann, G. M.P., Temple, P., \& Shurmer, M. 1996 Standards and trade performance: The UK experience. Economic Journal 106, 1297-1313.

Tassey, G. 2003 Methods for assessing the economic impacts of government R\&D, Geithersburg, MD., National Institute of Standards \&Technology.

Uyarra, E., Flanagan, K. (2010) Understanding the innovation impacts of public procurement. European Planning Studies, 18(1) 123-43.

von Hippel, E., 1986. Lead Users: A Source of Novel Product Concepts. Management Science, 32 (7) July, 791-805.

Wengel, J, Lay, G., Dreher, C., 1985. Evaluation of the indirect-specific promotion of manufacturing technology. In: G. Becher, S. Kuhlmann (eds.) Evaluation of technology policy programmes in Germany, pp.81-99, Dordrecht: Kluwer Academic Publishers Group, 1995 (Economics of Science Technology and Innovation)

Westling, H. 1996. Co-operative Procurement. Market Acceptance for innovative Energy-Efficient Technologies. IEA/NUTEK B1996.

Wilkinson R. Georghiou L, Cave J. et al 2005. Public procurement for research and innovation. European Commission, DG Research, EUR 21793. 